\title{
História e Direito: em busca dos continentes \\ submersos: comentário ao texto de Annick \\ Lempériere
}

DOI: $\underline{\text { http://dx.doi.org/10.1590/2236-463320171502 }}$

\author{
Wilma Peres Costa \\ Universidade Federal de São Paulo - UNIFESP, São Paulo - SP, Brasil \\ wilma_peres@uol.com.br
}

Resumo: Comentamos aqui a apresentação de Annick Lempériere, realizada no Colóquio Jurisdições, soberanias, administrações: a configuração dos espaços políticos na construção dos estados nacionais na América. O texto referência trata do "giro jurídico" na historiografia latinoamericanista e indaga sobre a contribuição dessa linhagem historiográfica para uma melhor compreensão da natureza e do papel do liberalismo na construção dos estados latino-americanos, tratado aqui como um liberalismo jurisdicional. O comentário remete à relação histórica das ciências sociais brasileiras com o campo do Direito e procura entender o modo como tem se expressado o referido "giro jurídico" na historiografia brasileira, enfatizando a relação fecunda entre as historiografias hispano-americana e brasileira em décadas recentes. Levanta, a partir daí, algumas temáticas compartilhadas por essas historiografias, procurando destacar o papel dessa zona de fronteira interdisciplinar na renovação não apenas da história política, mas também da história social.

Palavras-chave: História do Direito- História Política, Monarquia Constitucional, Escravidão 
Realizar o fórum da Revista Almanack no interior de um evento acadêmico abrangente, é sempre gratificante, pois nessas ocasiões se materializa um dos objetivos maiores do nosso periódico: deitar raízes nos territórios de pesquisa mais inovadores sobre o tempo/tema que mobiliza nossas inquietações e possibilitar as conexões entre redes de pesquisadores de diversos matizes, dentro e fora do Brasil. É com grande alegria que integro, portanto, essa sessão do Colóquio Jurisdições, Soberanias, Administrações: a configuração dos espaços políticos na construção dos estados nacionais na América, encontro que focaliza resultados provenientes das complexas e instigantes relações que têm se desenvolvido entre o campo da História e o do Direito nas últimas décadas e que conta com pesquisadores dispostos a percorrer (e às vezes a habitar) zonas de fronteira, sempre inquietadoras e fecundas. Dentre estas, ressalta-se nessa sessão o alcance (e os eventuais limites) do esforço intelectual designado como "giro jurídico", e que é um dos pilares da exposição que temos como tarefa comentar. Nos termos em que aqui se coloca - como uma ramificação da nova história política e da história intelectual - aquilo que aqui se designa como "giro jurídico" situa-se em um campo que poderíamos talvez designar como o de uma nova interdisciplinaridade, caracterizada pelo esforço de apropriação pelos historiadores de linguagens e conceitos cunhados em campos especializados (no caso o Direito e a História do Direito) e sua utilização para iluminar caminhos que vem sendo trilhados pela História Política nas construção do "objeto-estado" como problema historiográfico.

O diálogo que aqui travamos reveste-se de um significado especial também por uma outra razão. Ele é um momento de condensação de uma perspectiva que tem animado os grupos de pesquisa das várias instituições que gravitam em torno do Almanack - a busca da interlocução com a historiografia hispano/latino/americana, fruto de uma conviç̧ão historiográfica fortemente empenhada em ultrapassar aquilo 
que se poderia chamar de "paradigma do contraste". ${ }^{1}$ Entendemos por isso uma orientação longamente arraigada nas operações historiográficas sobre a América Latina, que buscava compreender o passado e projetar o futuro das nações que emergiram da crise do sistema colonial ibérico, a partir das diferenças entre do que ocorria no mundo de fala hispânica e naquele de fala portuguesa. No Brasil essa perspectiva tem raízes muito antigas, nas visões que aqui se estabeleceram no século XIX e buscavam uma formulação identitária que estabelecia uma alteridade externa (a América Espanhola) como mecanismo de compreensão da trajetória da América Portuguesa e do Brasil Independente. Como têm demonstrado muitos estudiosos, essa visão tinha como corolário uma alteridade interna (as populações autóctones e as massas escravizadas que faziam parte integrante do referido projeto nacional), e punha em relevo o papel civilizador da colonização portuguesa na construção da nacionalidade brasileira, que emergia, assim, como legatária de um passado, de um território e de uma soberania, que se consubstanciava na continuidade dinástica em solo americano, ainda que sob forma constitucional ${ }^{2}$. Coloco aqui ênfase na dimensão constitucional (que aproxima as experiências das duas partes do continente) por sobre a outra, a da monarquia (que as distingue) para chamar a atenção para o fato de que parte da renovação historiográfica que queremos sublinhar fez-se sobretudo pela valorização daquilo que a referida "historiografia do contraste" buscava conjurar: a importante interlocução entre as experiências constitucionais da Espanha e de Portugal nas primeiras décadas do século XIX e mais do que isso, a profunda impregnação do imaginário e da experiência política da Revolução do Porto e do Vintismo, nas lutas políticas da Independência e daquelas que se sucederam nas décadas seguintes. Aquele aprendizado político, com suas demandas de autonomia

\footnotetext{
${ }^{1}$ JANCSÓ, István (org.). Brasil: formação do Estado e da Nação. São Paulo: Hucitec, Unijuí, Fapesp, 2003 PIMENTA, João Paulo. A Independência do Brasil e a experiência hispano-americana (1808-1822). 1. ed. São Paulo: Hucitec, 2015. PIMENTA, João Paulo. Província Oriental, Cisplatina, Uruguai: elementos para uma história da identidade oriental (1808-1828). In: Marco A. Pamplona; Maria Elisa Mäder. (Org.). Revoluções de independências e nacionalismos nas Américas: região do Prata e Chile. São Paulo: Paz e Terra, 2007, p. 27-68.

2 SALGADO, Manoel, Nação e Civilização nos Trópicos: o Instituto Histórico Geográfico Brasileiro e o projeto de uma história nacional. Estudos Historicos, Rio de Janeiro, n.1, 1988, p.5-27.
} 
empalmadas pelas elites provinciais permaneceram vívidas e reverberando nas sucessivas revoltas e rebeliões contra o Rio de Janeiro, ocorridas nas províncias, pelo menos até 1848. Para os historiadores do século XIX, particularmente aqueles alinhados com a visão do Instituto Histórico e Geográfico Brasileiro, afirmar o contraste com a América Espanhola tinha o sentido não apenas de conjurar os temores da república ou da fragmentação política, mas também a herança de apego às franquias e liberdades provinciais legada pelo Vintismo, e com ela a experiência compartilhada com a experiência do constitucionalismo de Cádiz, na forma como ele foi vivenciado na América. Não por acaso, a ultrapassagem daquele paradigma tem trazido resultados relevantes precisamente no estudo comparado e conectado sobre a experiência constitucional de Cádiz e suas reverberações nos dois mundos e nas duas partes da América Ibérica. ${ }^{3}$ Lembro essa trajetória recente, não apenas por que ela tem sido cara a toda uma geração de pesquisadores para pontuar que a temática que aqui tratamos hoje é um dos exemplos mais conspícuos desse território comum que construímos e que, como tantos outros, devemos à inspiração e a experiência consolidada de nossos colegas europeus e latino-americanos envolvidos nessa renovação.

No Brasil, o interesse pelo tema é relativamente novo, embora crescente e promissor ${ }^{4}$, o que nos faz enfatizar a importância do presente evento, oportunidade privilegiada de ouvir, aprender e debater trabalhos de alguns dos pesquisadores que tem sido referência nesse campo, na Europa e na América Espanhola, junto aos pesquisadores brasileiros que têm sido pioneiros nesses estudos no Brasil. A presença entre nós da Profa. Annick Lampérière se traduz, nesse sentido, em uma ocasião privilegiada, por se tratar de um dos principais expoentes da grande renovação da História Política sobre a Hispano-América ${ }^{5}$, iniciada por François Xavier-Guerra ${ }^{6}$, cujas

\footnotetext{
${ }^{3}$ BERBEL, M. R., OLIVEIRA, C. H. S. (Org.) . A experiência constitucional de Cádis - Espanha, Portugal e Brasil. São Paulo: Alameda, 2012

${ }^{4}$ Ver, por exemplo, FONSECA, R.M. (coord.) As Formas do Direito - Ordem, Razão e Decisão (Experiências Jurídicas Antes e Depois da Modernidade). SP: Juruá, 2013.

${ }^{5}$ LEMPÉRIÈRE, A. Entre Dieu et le roi: la république. Mexico XVIe-XIXe siècles. Paris, Les Belles Lettres, 2005. Trad. Espanhol, Entre Dios y el rey: la república. La ciudad de Mexico de los siglos XVI al XIX, México, Fondo de Cultura Económica, 2013. Ver também LEMPÉRIÈRE, Annick. "La Historiografía del
} 
seminais contribuições reverberam nos trabalhos de toda uma nova geração de historiadores do mundo hispano e luso- americano. Do mesmo modo, é uma grande honra dividir essa mesa com a Profa. Marcela Ternavasio ${ }^{7}$, refinada especialista da História Política do Rio da Prata, com quem tanto temos aprendido sobre esse espaço de experiência compartilhada cujas conexões com a América Portuguesa engendram agendas de pesquisa desafiadores para os investigadores da história dessa vasta região, marcada por turbulências, olhares cruzados, utopias e tragédias em comum. Inscrevo-me aqui como uma historiadora que, embora não tenha feito incursões especializadas sobre a temática do jurídico e de suas instituições, tem denodadamente defendido a importância de se encarar o estado como objeto da história e que, acima de tudo, tem um fascínio incontrolável pelos territórios de fronteira, reais, virtuais ou metafóricos.

Na primeira parte do texto proposto para discussão, Annick Lempériere divide conosco reflexões sobre o giro jurídico em um espaço-tempo particular - a crise do Antigo Regime e sua articulação com a formação dos estados latino-americanos, vale dizer, as últimas décadas do século XVIII e as primeiras do século XIX. Partindo de uma visão crítica sobre a relação que os historiadores latino-americanistas têm tradicionalmente mantido com o universo jurídico, relação que não leva em conta a especificidade daquele universo, a autora coloca em relevo a importância do "giro jurídico" como ferramenta heurística potencialmente enriquecedora para os historiadores do ofício, mas procura problematizar as distinções e aproximações possíveis entre "o olhar do jurista" e "o olhar do historiador". Na segunda parte seu olhar se dirige para uma temática específica - o liberalismo - para indagar se as

Estado en Hispanoamérica. Algunas reflexiones". In: PALACIO, Guillermo (Coord.). Ensayos sobre la nueva historia política en América Latina, siglo XIX. México: Colegio de México, 2007, 45-62.

6 GUERRA, François-Xavier. México: del Antiguo Régimen a la Revolución: México: FCE. 1988; Modernidad e independencias: ensayos sobre las revoluciones hispánicas, Madrid, MAPFRE, 1992, e também Las Revoluciones hispánicas: independencias americanas y liberalismo español, Madrid, Editorial Complutense, 1995.

${ }^{7}$ Ver, TERNAVASIO, M., Gobernar la revolución. Poderes en disputa en el Rio de la Plata, 1810-1816, BA. Siglo Veintiuno. Ver também, nas interfaces aqui mencionadas TERNAVASIO, M. Candidata a la corona : la infanta Carlota Joaquina en el laberinto de las revoluciones hispanoamericanas. BA, Siglo Veiuntiuno Editores, 2015 
contribuições recentes dessa aproximação dos historiadores do universo jurídico, possibilitam construir um conceito de liberalismo que seria particular desse tempo/lugar - a América Latina da crise do Antigo Regime à construção dos estados nacionais - um liberalismo jurisdicional. Este, olhado através do seu sedutor convite, no espelho do direito, caracteriza-se pela interlocução entre uma ordem constitucional ao mesmo tempo abrangente e distante - a Constituição de Cádiz- enquanto que o longo interregno de desmoronamento do sistema metropolitano não foi acompanhado de uma derrogação explícita de sua respectiva ordem jurídica. Vale dizer que uma multiplicidade de textos e normas jurídicas - o direito comum engendrado no Antigo Regime, as normatizações metropolitanas tradicionais e os preceitos constitucionais de Cádiz - passaram a conviver na ausência de códigos que dessem positividade ao novo direito. Uma permanência da ordem tradicional mais longa do que habitualmente a historiografia política estava disposta a reconhecer (o olhar do historiador) é um dos corolários desse pressuposto. Quero crer que não violento a ideia central do texto ao considerar que o outro corolário nasce da ideia da uma "revolução política sem revolução jurídica", seria a sobrevalorização não da lei, mas daquele que a dita, vale dizer, a permanência de uma "justiça de juízes", ao mesmo tempo carente de codificações e resistente a elas.

Nos estudiosos desse tema na América de fala espanhola, o referido liberalismo jurisdicional lançaria suas raízes nessa reversão do poder para os pueblos, as corporações territoriais e as elites locais, no longo interregno político iniciado com o desaparecimento da figura real. Desse modo, creio novamente estar sendo fiel ao pensamento de Annick, ao entender que aqui se inscreve claramente a ideia de uma temporalidade alargada, que coloca em campos claramente distintos o processo de Independência e aquele da construção do Estado. Não posso deixar de manifestar minha alegria ao ver essa temática colocada com meridiana clareza por que acredito que ainda medra na historiografia brasileira uma certa resistência em reconhecer isso, mantendo a tendência a subsumir essa diferença em uma continuidade políticoadministrativa em que o estado nacional emerge quase como um desdobramento 
natural da administração metropolitana, em particular dos mecanismos criados na América com a vinda da corte, em 1808. Penso que o recorte proposto nos permite destacar com clareza esse período, atravessado por turbulências de toda ordem que ocupou, nas duas partes da América Ibérica, pelo menos toda a primeira parte do século XIX e olhar para ele em sua especificidade. É no interior dessa periodicidade alargada que se insere essa mescla de antigas práticas em convívio com uma ordem jurídica nova (porém não codificada) que ganha sentido a concepção de um liberalismo jurisdicional. Dentre outras diferenciações, esse liberalismo se assentaria sobretudo na defesa das liberdades locais, recém adquiridas pela ausência do poder monárquico que as submetia secularmente gerando o prolongamento e a reiteração de práticas jurídicas próprias do Antigo Regime, em complexa interação com a ordem constitucional "moderna" construída a partir dos preceitos gaditanos. A identificação e o estudo das práticas jurídicas e políticas desse liberalismo, entretecida nas localidades e resistente à imposição de um centro político, poderiam ajudar a compreender a emergência de uma outra cepa liberal, a partir da segunda metade do século XIX, esta marcada por práticas autoritárias e centralizadoras exatamente em reação à anterior preeminência do liberalismo jurisdicional. Podemos supor que este interregno jurisdicional do liberalismo teria operado como uma fonte de resistência ao processo de construção do Estado, entendido este, entre outras características, como a capacidade de exercer a jurisdição sobre o território e controlar a ordem jurídica. 0 liberalismo de cepa "jurisdicional » da primeira metade do século seria, de certa maneira, o casulo das práticas autoritárias daquele que vai emergir na segunda metade, sendo o México um exemplo paradigmático dele. Creio que o tema ganha ainda maior clareza se buscarmos a noção de liberalismo que está sendo mobilizada por Annick Lempérière, em fonte citada em seu artigo, onde este é confrontado à ideia de republicanismo no contexto da revolução francesa, estabelecendo-se entre os dois ideários políticos uma relação de filiação mais do que de oposição.

Il faut poser la question de la définition d'une "république ", c'est-à-dire d'un régime institutionnel et social qui apparaisse non comme un 
instrument d'assujettissement de certains individus à certains autres, mais comme un instrument général de libération et d'autonomisation. En un moment social où les liens communautaires fondés sur des croyances partagées ont largement laissé la place à un extraordinaire pluralisme des convictions et des modes de vie, le fondement de la légitimité des institutions ne peut en effet plus se trouver que dans la justice, c'est-à-dire dans une forme de régulation sociale qui garantit à chacun qu'il n'est pas l'instrument de l'indépendance des autres et qu'il possède autant de chances que quiconque de donner corps à ses propres projets. En son acception moderne, la théorie politique républicaine est donc une théorie de la légitimité de l'autorité et des règles collectives dans une société d'individus séparés; elle affirme que, dans un contexte de ce genre, les individus ne sont libres que si les règles sont légitimes et que, à leur tour, les règles ne sont légitimes que si elles peuvent rationnellement être considérées par tous non comme des outils de pouvoir mais comme des instruments d'affranchissement. ${ }^{8}$

A referida citação deixa evidente, entre outros temas que aborda, a intima relação entre a noção de liberdade que emerge da revolução francesa, e que será mantida nas décadas subsequentes, como estando associada à legitimidade e à codificação das regras que organizam a convivência comum de indivíduos separados, não mais de membros de corpos ou comunidades tradicionais. Distinto deste, o liberalismo latino-americano, jurisdicional ou "autoritário" seria distinto daquele que se desenvolveu após a revolução francesa, na sua própria acepção de liberdade e na sua diversa relação com a ordem jurídica.

Como uma leitora interessada dos trabalhos que se alinham com o referido "giro jurídico", e como historiadora do político, sou entusiasta das temáticas que o sugestivo trabalho de Annick Lempériere nos convida a visitar e reconheço força sugestiva da sua proposta não apenas para o México, de onde as reflexões principalmente partem. Inspirada nessas sugestões, e tentando pensar a partir da experiência histórica brasileira em direção a uma agenda compartilhada de pesquisa, menciono aqui alguns pontos visando a contribuir para a discussão de um tema clássico, sobre o qual se lançam novos e promissores olhares.

Olhando a partir do Brasil e da trajetória formativa das ciências sociais brasileiras no século XIX, é inegável que sua intersecção com o campo dos estudos

8 SPITZ, Jean-Fabien. Républicanisme et libéralisme dans le moment révolutionnaire. Annales historiques de la Révolution Française, n. Paris, n. 4, out-dez, 2009, p. 21-47. 
jurídicos é bastante antiga. Mais do que isso, e talvez esse seja um ponto importante a sublinhar, a imantação daquelas ciências pelo direito foi constitutiva do modo como foram introduzidas no ensino e na reflexão das camadas letradas, levando-se em conta que a universidade foi uma construção tardia, sendo o direito, a medicina e a engenharia (essa de origem nos cursos militares), as únicas formas de estudos superiores disponíveis até a década de 1930. Foi no interior dos cursos de direito que no Brasil se engendrou não apenas a Sociologia como também a Economia, enquanto que a medicina seria o locus da nascente antropologia, já bem avançado o século XX. Desse modo, não apenas a ideia de "estado" como aquela de "sociedade" foram, no Brasil, forjadas nos cursos jurídicos. Foi também aí que encontrou abrigo boa parte do ensaísmo histórico que impregna ainda hoje nossas agendas de pesquisa. Para focalizar em um ponto especialmente sensível para a discussão do liberalismo e suas configurações, vale lembrar que foi pensando o Brasil e procurando interpretá-lo "no espelho do direito" que se formulou a célebre dicotomia cristalizada nas obras hoje clássicas de Nestor Duarte e Raimundo Faoro, em que o primeiro percebia a história brasileira como o espaço do domínio secular das elites agrárias, espaço em que a ordem privada criava um óbice permanente e reiterado à construção da ordem jurídica e da esfera pública, enquanto que o segundo, em percepção diametralmente oposta, identificava um Estado hipertrofiado e onipresente, através de uma camada de burocratas que garroteava uma sociedade civil enfraquecida, onde o liberalismo e a cidadania não conseguiam prosperar $^{9}$. A sociologia política produzida pelos juristas foi a responsável pela introdução dos conceitos weberianos, e imprimiu profundas marcas nas ciências sociais brasileiras e na agenda dos historiadores. Para os que começaram os seus estudos em Ciências Humanas inspirados por essa dicotomia, seu caráter mais curioso e instigante era precisamente que, lidas com honestidade intelectual e considerando seus pressupostos, cada uma delas parecia dotada de uma grande força de convencimento e poder explicativo da realidade brasileira. Talvez o mais influente e

9 DUARTE, Nestor. A ordem privada e a organização nacional (contribuição à sociologia política brasileira). SP: CEN, 1939; FAORO, Raymundo. Os donos do poder - formação do patronato político brasileiro. Porto Alegre, Editora Globo, 1958. 
ainda hoje bastante pertinente ensaio nessa tradição histórico-jurídica seja o de Vitor Nunes Leal, que no seu estudo célebre tratava de pensar as raízes e os efeitos da dualidade paradoxal entre o mandonismo local dos currais eleitorais e o papel subalterno das municipalidades na ordem jurídica brasileira do Império e da Primeira República ${ }^{10}$. O ser bifronte que essa perspectiva permitia divisar foi mesmo designado com o auxílio da mitologia, como um Minotauro, em um dos melhores estudos que procuraram fazer do aparente paradoxo uma agenda de pesquisa ${ }^{11}$. Juristas brilhantes e militantes da institucionalidade democrática, esses autores procuravam, a partir do saber jurídico e dos conceitos sociológicos aí apreendidos pensar a sociedade e o estado no Brasil.

Em outro ponto do espectro político, juristas de extração mais conservadora, mas também de forte inspiração sociológica, como Oliveira Vianna, tematizaram um suposto "descolamento" entre o país legal e o país real e cristalizaram a visão de um sistema constitucional "artificial", inadequado, baseado em ideias exógenas, incapaz de produzir a ordem sem o auxílio de um estado forte, capaz de vertebrar a ordem social e fazê-la amadurecer para a cidadania plena. ${ }^{12}$

Embora desembocando em distintos diagnósticos e posturas políticas, o que caracterizava esse movimento que vinha do campo jurídico para a análise era a busca de constantes históricas, de taxonomias, que voltavam o olhar para o passado, em geral para as raízes ibéricas e para a natureza pouco vertebrada da vida social. Mas o debate que eles propunham envolvia o questionamento do liberalismo, que era assim matizado e qualificado, mas não o era a partir do estudo da esfera jurídica. O direito era o lugar de onde provinham, aquela espécie de onipresente/invisível que nos apontou Annick Lampérière, parafraseando o que afirmara Pierre Rosanvallon ao tratar do Estado em seu livro-programa.

O movimento que temos em tela e que desenha uma nova convergência entre o campo do Direito e aquele da História é distinto do que acabamos de mencionar por

\footnotetext{
${ }^{10}$ LEAL. Vitor Nunes. Coronelismo, enxada e voto. RJ: Forense, 1948.

${ }^{11}$ URICOECHEA, Fernando. O minotauro imperial. São Paulo, Difel, 1978.

12 VIANNA, F.J.O., O idealismo da constituição RJ Sol e Terra, 1927, entre muitos outros.
} 
diversas razões, mas a mais evidente me parece ser a de que ele não parte de hierarquias fixas entre os campos do saber, mas da busca de um reconhecimento de diferenças de abordagens e linguagens e em diálogo mais igualitário entre saberes ${ }^{13}$. Os problemas vividos no presente nas várias partes do mundo ocidental e que se conectam de diversos modos com a crise estendida desse nosso tão caro objeto de análise - o estado-nação - cristalizada, entre outros pontos, na crescente corrosão do prestígio dos sistemas de representação política, têm exacerbado a visibilidade da esfera jurídica engendrando formas diversas de judicialização da política, assim como do seu par dialético - a politização da justiça. O fenômeno, visto com preocupação por alguns, como fonte de novas e promissoras possibilidades, por outros, tem sido um dos corolários dessa aproximação entre juristas e historiadores, que tem tido nos neoconstitucionalistas uma das suas expressões mais desafiadoras. Embora não seja este meu campo de estudos, creio não estar enganada ao supor que a faceta mais claramente politizada desse movimento tem se enraizado sobretudo no campo jurídico, reverberando sobre os cursos de Direito e dando uma importância alargada às disciplinas vinculadas à História do Direito. Na historiografia referente à América Espanhola, as contribuições de uma agenda compartilhada entre historiadores e juristas tem incidido sobretudo na análise da derrocada do sistema colonial espanhol e na formação dos estados-nações de fala espanhola na América, nas primeiras décadas do século XIX. Poderíamos arriscar talvez a afirmação de que os juristas/historiadores têm se movido sobretudo a partir da crise do estado-nacional, enquanto os historiadores/juristas têm se interessado, nomeadamente, sobre a sua gênese, tema que reúne a maioria dos estudos do chamado giro jurídico.

Olhando do ponto de vista dos historiadores de ofício entendo que o forte movimento atual em direção ao campo jurídico aqui representa um empreendimento de muitas faces. Duas ganham evidência especial: em primeiro lugar, o esforço de apropriação de um vocabulário específico - o do Direito - de modo a internalizar como

${ }^{13}$ GARRIGA, Carlos, ¿La cuestión es saber quién manda? Historia política, historia del derecho y "punto de vista", PolHis • Año 5. Número 10. Segundo semestre 2012. pp. 90-100. 
problema de pesquisa o conteúdo propriamente jurídico das fontes utilizadas; a partir daí, reconhecer a impregnação do tempo sobre esse mesmo vocabulário e desenvolver a capacidade de interrogá-lo a partir desses mesmas fontes vale dizer, de empreender sua decodificação. Trata-se, como se sabe, de empresa difícil e também, por que não dizer, perigosa, pois a linguagem jurídica é dotada de grande autonomia e de regras próprias, armadilhas retóricas e encantamentos. Lembro-me aqui de um trecho do historiador Carlos Garriga que evidencia esse desafio ao mesmo tempo difícil e incontornável das intrincadas relações entre a História e o Direito na construção histórica dos estados nacionais.

Esta monumental tarea expropiatoria (por utilizar el término del mismo Weber que cuajó esa noción) en que vino a resolverse el proceso de construcción del Estado nacional, exigió una potente operación ideológica, en la cual la historia como disciplina asumió el cometido de naturalizar la idea estatal, construyendo el Estado en el pasado para presentarlo como la forma política propia o consustancial al hombre socialmente organizado. [...]El Estado (sin adjetivos) ya no es sólo un nombre más o menos preciso para cierta cosa, una organización política dada, sino que envuelve toda una concepción acerca de cómo deba configurarse la dominación politica, que responde en lo sustancial a la forma como resultó políticamente organizada, mediante un proceso complejo y muy conflictivo, la sociedad europea posrevolucionaria, el llamado Estado liberal o de derecho. Esta tarea, que llena historiográficamente el siglo XIX y buena parte del XX, consistió en un auténtico y muy eficaz proceso de invención de la tradición, que discurrió de modo rigurosamente paralelo a la construcción histórica de la identidad nacional (para la cual fue originariamente acuñada esa expresión), con la que en rigor se confunde. ${ }^{14}$

Penso que a percepção do enredamento histórico do fenômeno-estatal, das identidades políticas coletivas sob forma nacional e da própria disciplina histórica dão o nexo explicativo da visão que hoje desenvolvemos sobre o século XIX e que alimenta os vários "giros" que tem atravessado nosso ofício, nesse afã reflexivo de tornar o estado, a nação e a própria disciplina histórica, em objetos da história. Nesse sentido, no que toca o "giro jurídico" da história política, tratamos de um processo de apropriação de linguagem, por certo, mas, sobretudo, de um trabalho de tradução, de desnaturalização do campo do Direito, uma vez que a disciplina histórica de que aqui

${ }^{14}$ GARRIGA, Carlos. Ordem jurídico y poder político en el Antiguo Régimen. Istor, México, n. 16. Disponível em www.istor.cide.edu/revistaNo16.html, Acesso em 01 de fevereiro de 2017. 
tratamos não é um repertorio de conhecimentos (embora este seja importantes e mesmo indispensáveis) mas um modo de conhecimento, que se vale das ferramentas da externalidade e da diacronia. É dessa forma que ele pode operar a "desnaturalização" através desse complexo mecanismo de olhar para algo que é extremamente familiar como "coisa não sabida". ${ }^{15}$ Ora, para aqueles que tomam o estado como objeto historiográfico isso significa que o desafio é enorme porque o estado produz seu próprio discurso legitimador e o direito é precisamente o núcleo significativo desse discurso. Vale dizer que o estudo histórico do Direito é tarefa fundamental para submeter os estados ao escrutínio da história, fazendo com que ambos deixem de ser o onipresente-invisível de que nos fala Annick convergindo com Rosanvallon. ${ }^{16}$

Um segundo ponto que gostaria de lembrar, e que se desdobra do anterior - a apropriação de uma linguagem dotada de regras próprias - é a sugestiva metáfora de Paolo Grossi, em sua generosa esperança da contribuição dos historiadores do direito para a renovação daquela disciplina.

É o historiador quem pode e deve recordar aos privativistas e aos publicistas - todos eles presos nos próprios textos legislativos - o fato de que o texto em si é sempre representação de uma realidade de fundo, uma representação parcial e artificiosa por somatória. $O$ fato de que o texto é como o cume emergente de um continente submerso, sendo enganosa a observação da parte visível, o que torna necessário o mergulho para que se possa apreciar a substância efetiva do fenômeno. A partir desta referência a todo o resto situado além e abaixo das normas, e a conseqüente complexidade do mesmo universo jurídico, somente uma figura reúne condições para realizar a tarefa: o historiador. De fato, é ele que ouve com toda sua integridade quem está voltado não a isolar, mas a captar nexos, implicações, raízes. Quando retomamos consciência de todos os extratos do jurídico, a lição metodológica da história se torna preciosa. ${ }^{17}$

Das duas citações anteriores, gostaria de reter, para nossa discussão, a

${ }^{15}$ GARRIGA, Carlos.¿La cuestión es saber quién manda? Historia política, historia del derecho y "punto de vista". PolHis. Año 5, n. 10, Segundo semestre 2012, p. 90-100

${ }_{16}$ LEMPÉRIÈRE, Annick. La Historiografía del Estado en Hispanoamérica. Algunas reflexiones. In: PALACIO, Guillermo (Coord.). Ensayos sobre la nueva historia política en América Latina, siglo XIX. México: Colégio de México, 2007, 45-62.

${ }^{17}$ GROSSI, Paolo, O ponto e a linha. História do Direito e Direito Positivo na formação do jurista do nosso tempo. Revista Sequencia, Florianópolis/SC, vol. 26, n. 51, dez 2005, p. 31-45, 
pertinência desse duplo movimento - por um lado, a apropriação de uma linguagem (a do direito pela história), que é também a condição de que se opere a sua desnaturalização; por outro, esse retorno necessário sugerido por Paolo Grossi, para uma dimensão que conecta o texto, como cume, ao seu próprio continente submerso, vale dizer, a alguma coisa a qual se tem acesso a partir do texto, mas que está além dele. Creio que a chave aqui pode estar em algo que sempre esteve nos nossos discursos, mas não necessariamente em nossas agendas de trabalho - refiro-me ao caráter expropriatório dessa pulsão (nem sempre atendida) inseparável da construção do poder do estado sobre territórios e populações. Vale dizer que os chamados monopólios que caracterizam o Estado (da violência, do exercício do direito) não são dados mas processos que se repõem a todo tempo, retirando poderes de localidades, regiões, indivíduos, de corporações. Vale dizer: o continente submerso no qual devemos mergulhar está sempre perpassado pelo conflito. É evidente que este pode se resolver pela rendição a uma força maior, porém, como as experiências históricas latino-americanas tem demonstrado com força, ele também pode desembocar em transações e reinvenções de vários matizes, que só a pesquisa histórica pode trazer a luz.

Vale dizer que quando tratamos da construção das instituições jurídicas e da extensão de sua vigência tratamos sempre também de resistências daqueles que terão poderes diminuídos (ou liberdades ameaçadas) por aquela ordem. Estes podem ser grandes senhores rurais, proprietários de escravos, senhores da guerra, mas podem ser também homens livres pobres, frequentemente forros que continuam a viver sob seu domínio. Podem ser vastos contingentes de populações indígenas que operam nas franjas da ordem e que manejam instrumentos próprios de sobrevivência, domínio, controle, que podem se opor ao estado (e frequentemente o fazem). O que significa também que temos que investigar sobre a eficácia das tradições reais ou inventadas com as quais as populações ordenam seus conflitos dentro ou fora da ordem legal instituída.

Tratando do Brasil, gostaria de apontar duas questões para a nossa discussão. 
Em primeiro lugar, sem desejar recair no "paradigma do contraste" não é demais lembrar as diferenças profundas que marcaram a experiência das duas partes da América Ibérica a partir de 1808, no período cujo estudo tem sido caro aos historiadores alinhados com o giro jurídico. Refiro-me à presença da Corte no Brasil entre 1808 e 1822 e viabilização da solução monárquica que se seguiu, com conflito armado intenso, mas de curta duração. Precisamente a presença mais próxima do Monarca foi o que caracterizou o desdobramento da crise europeia criando um efetivo centro político na América que, longe de permitir uma autonomia maior das províncias, buscou, no plano jurídico, fiscal e administrativa, estreitar as relações entre esse centro, que se tornava o centro da governança do Império, e suas partes. ${ }^{18}$ Esse movimento gerou, como tem demonstrado muitos estudos, tanto aproximações como fundas resistências às imposições metropolitanas. Nesse contexto é que o constitucionalismo proposto pela Revolução do Porto tornou-se atraente para as capitanias (que agora se tornavam províncias), precisamente por que parecia acenar com a consolidação de autonomias que elas almejavam e que de fato vinham, algumas delas, sendo contempladas desde as Reformas Pombalinas. As tensões que aí emergiram entre uma experiência política que parecia contemplar algumas das demandas das elites provinciais (particularmente as do Norte) e o centro político que veio a se consolidar no Rio de Janeiro, com uma outra Constituição proposta por D. Pedro I, parecem ter reverberado nas décadas subsequentes, alimentando inclusive as rebeliões que eclodiram ainda na década de 1820 e recrudesceram a partir da Abdicação. Nesse conflito, e na sua solução que atendeu várias das demandas propostas pelas elites provinciais, que se consagram sobretudo a partir do Ato Adicional (1834), a justiça eletiva proposta e apoiada pelas primeiras foi fortemente esvaziada de suas atribuições e o judiciário permaneceu sob controle do estado

${ }^{18}$ COSTA, Wilma Peres. Travessias: algumas percepções dos enlaces entre a Europa e a América na crise do Antigo Regime. In: Oliveira, Cecilia H. de Salles; Bittencourt, Vera L. N.; Costa, Wilma P.. Soberania e conflito: configurações do Estado nacional do Brasil do século XIX. São Paulo: FAPESP/Hucitec, 2010, p. 27-63. 
central. ${ }^{19}$ Ainda no campo das diferenças, vale lembrar a frágil estrutura urbana que se desenvolveu nos três séculos de colonização, caracterizada sobretudo pelo poder dos grandes potentados rurais, em forte contraste com essa viva vida comunitária dos pueblos hispano-americanos.

Relembro esses pontos sobejamente conhecidos para incidir sobre um ponto levantado pelo texto que ora discutimos - a ideia de um liberalismo jurisdicional e as possibilidades que para o seu entendimento são oferecidas por uma aproximação mais fecunda da esfera do direito. Vale dizer que consideramos que essa é uma forte convergência, sendo o fenômeno da justiça dos juízes e a aversão às codificações, uma marca muito forte do século XIX brasileiro, e até além. Basta lembrar que o Código Civil no Brasil só veio a existir no século XX. Para que o potencial heurístico da aproximação entre a História e o Direito ganhe sua plenitude, penso que é necessário também levar em conta a extraordinária opacidade gerada pelo escravismo, escravismo que, longe de ser um resíduo colonial, se colocava mesmo como um projeto profundamente entretecido com o Estado Nacional. Convivendo com a ilegalidade do tráfico desde 1831, os interesses ligados ao comércio e à posse de escravos tiveram sempre funda resistência às matrículas, aos cadastros, aos censos e a quais quer formas de normatização que viesse a penetrar o espaço privado das fazendas, inclusive aquelas referidas à legalização das propriedades territoriais. ${ }^{20}$ Penso que a ideia de um liberalismo jurisdicional pode ser bastante operativa para pensar a trajetória brasileira, mas ela deve ter em conta que nessa experiência, marcada pela presença da ordem monárquica e pela escravidão, a tensão não é entre jus commune presente nas comunidades e a ordem jurídica racional-modera, mas entre esta e a parte que fica fora dessa ordem, à sua margem, ou nas suas bordas - penso sobretudo nas

\footnotetext{
${ }^{19}$ SLEMIAN, Andréa. Sob o império da lei: constituição e unidade nacional na formação do Brasil (18221834). São Paulo: Hucitec, 2009. SLEMIAN, Andréa. A administração da justiça nas primeiras décadas do Império do Brasil: instituições, conflitos de jurisdições e ordem púbica (c.1823-1850). Revista do Instituto Histórico e Geographico Brazileiro, Rio de Janeiro, 2011, v. 452, p. 225-272. Para a engenharia do estado nacional e a negociação do espaço político das elites regionais ver DOLHNIKOFF, Miriam. $O$ pacto imperial: origens do federalismo no Brasil do século XIX. São Paulo: Globo, 2005.

20 SILVA, Ligia Osorio. Terras devolutas e latifúndio. In: de 1850. Campinas: Unicamp, 1996

. Terras devolutas e latifúndio: efeitos da lei
} 
comunidades indígenas, nos habitantes dos sertões e na escravaria dos engenhos e fazendas. Esta, parte integrante do projeto do Estado Monárquico constitucional, tem suas bases na ilegalidade do tráfico de escravos, reconhecida oficialmente desde 1831, porém burlada pelas estratégias conjuntas de agentes públicos, traficantes e fazendeiros. A discussão passa também pelo estudo mais apurado do papel da Igreja e da reinvenção peculiar do padroado que foi empreendida pela Monarquia Constitucional, mantendo o papel de controle que esta tem sobre a ordem civil.

Concluo aqui sugerindo que, se o papel do historiador, ao empreender a viagem em direção à uma linguagem especifica, é abrir caminhos para o continente submerso que subjaz a ela - o tecido social e os conflitos que o recortam. Toda viagem, em última instância, pressupõe um retorno.

Data de recebimento do Artigo : 13/02/2017

Data de aceite do Artigo : 03/03/2017 